\title{
A New Mobile Payment Method for Embedded Systems Using Light Signal*
}

\author{
Hoyoung Hwang ${ }^{1}$, Moonhaeng $\mathrm{Huh}^{2}$, Siwoo Byun ${ }^{2}$, and Sungsoo $\mathrm{Lim}^{3}$ \\ ${ }^{1}$ Department of Multimedia Engineering, Hansung University, Korea \\ hyhwang@hansung.ac.kr \\ ${ }^{2}$ Department of Digital Media Engineering, Anyang University, Korea \\ \{moonh, swbyun\} @anyang.ac. kr \\ ${ }^{3}$ Department of Computer Science, Kookmin University, Korea \\ sslimakookmin.ac.kr
}

\begin{abstract}
This paper presents a new type of digital payment method and algorithm for embedded systems including mobile phone and other handheld devices. In the conventional mobile payment system, a payment signal transmitting device and a wireless internet connection device are separately provided to mobile systems. Therefore, the production cost of the mobile devices increases, and the complexity and the size of the mobile devices grow. In order to solve the problems, a new digital payment method using light signal containing payment-related information is suggested for mobile phone and embedded devices. The new method provides an economic and efficient solution to mobile payment system by updating embedded software without need of additional hardware modules to mobile devices.
\end{abstract}

\section{Introductions}

The trend of digital and mobile convergence in IT technology brings multifunctionality to mobile embedded devices including phones and PDAs. As a result, various functions such as digital camera, camcoder, mp3 player, which were produced and purchased as independent devices before are now integrated in a single phone or embedded device. One of those functionalities is digital cash or payment system.

In recent years, several mobile payment methods or systems have been developed in order to avoid the inconvenience of carrying cash or credit card [1]-[7]. Those payment systems are mainly used for mobile phone devices and mostly for smallvalued payment. However, in conventional mobile payment systems, a payment signal transmitting device and a wireless internet connection device are separately provided to the mobile phone or embedded devices. Therefore, the production cost of the mobile phone or devices increases, and the complexity and size of the mobile devices grow. In addition, there is another critical problem in that the users who want to use the mobile payment system may need to purchase a new phone or devices with additional hardware functions.

In order to solve the aforementioned problems, a new mobile payment method is proposed. The method is implemented by updating embedded software of a phone

\footnotetext{
* This research was financially supported by Hansung University in the year of 2007.
} 
without the need of additional hardware modules to the existing mobile phone or devices. In the proposed method, a virtual mobile card containing payment-related information is loaded to the virtual machine in the mobile phone or embedded system OS. The virtual mobile card can comprise various types of payment-related information such as credit card number, membership card number, discount coupon image, online ticket, etc., which are downloaded from a control server and stored in the mobile phone or devices. The virtual mobile card information is transmitted by image by blinking the backlight of the LCD/LED panel of the mobile devices, and the transmitted information is decoded by the photo receiver which is designed for the proposed mobile payment system. The data transmission function is implemented by embedded software that controls the lightning device of a phone or handheld systems, which can be applied to the most mobile phone already in use.

In the following Section 2, the characteristics of existing mobile payment systems are presented and compared with the proposed method. Section 3 describes the proposed mobile payment system model and its detailed subsystems; the mobile phone, the photo receiver, and the control server. Section 4 presents the payment procedure of the proposed method, and Section 5 summarizes the paper.

\section{Mobile Phone Payment Systems}

In Korea, it is believed that normally 4 or 5 credit cards are owned and carried per adult person in addition to transportation card, debit card, membership card, ID card, and etc. [8] There is a problem in that, when the cards are lost or stolen, the owner may suffer a great deal of damages. In order to solve the inconvenience of carrying various cards, several approaches have been tried to put those card information into a phone or other embedded devices. The approaches include barcode-based solution, and IR/RF-based solution as presented in Table 1.

Some telecom companies adapted barcode type membership card into mobile phones and used it as mobile payment and membership authentication[9]. This method is easy to implement and widely applicable to membership management applications. The weak point of this method is that the information being contained by a barcode is very limited. Moreover, if conventional laser type barcode reader devices are used, many transmission errors occur because of the reflection problem on the surface of the display device of a phone. Therefore, CCD type reader device is needed which increase the cost of system. In addition, barcode type information can be easily copied thus incurs security problem.

More widely adapted mobile payment method is using IrDA (Infrared Data Association) or RFID (Radio Frequency Identification) technology to integrate payment related information into a phone or embedded devices[10]. This method shows high ability of processing large volume of data and multimedia applications, and provides high level of security management functions. However, the shortcoming of this method is that it requires additional hardware modules. Therefore, users should have specialized phones or devices with the additional hardware module instead of existing devices already in use, which makes widespread use of this method difficult. 
Table 1. Characteristics of mobile payment methods

\begin{tabular}{|c|c|c|c|}
\hline & Proposed Method & Barcode & $\mathrm{IR} / \mathrm{RF}$ \\
\hline $\begin{array}{l}\text { Additional } \\
\text { Hardware }\end{array}$ & $\begin{array}{l}\text { No Need. } \\
\text { Use the existing back- } \\
\text { light of phone devices }\end{array}$ & $\begin{array}{c}\text { No Need. } \\
\text { Barcode image. }\end{array}$ & $\begin{array}{l}\text { Need. } \\
\text { RFID or smartcard chip } \\
\text { required }\end{array}$ \\
\hline $\begin{array}{l}\text { Reuse } \\
\text { existing } \\
\text { devices }\end{array}$ & $\begin{array}{c}\text { High. } \\
\text { Adaptable to all the } \\
\text { existing phone de- } \\
\text { vices }\end{array}$ & $\begin{array}{c}\text { High. } \\
\text { Adaptable to all the } \\
\text { existing phone devices }\end{array}$ & $\begin{array}{c}\text { Low. } \\
\text { Need to purchase a } \\
\text { new devices }\end{array}$ \\
\hline Security & $\begin{array}{c}\text { Yes. } \\
\text { security s/w module } \\
\text { needed }\end{array}$ & $\begin{array}{c}\text { No. } \\
\text { Easily copied }\end{array}$ & $\begin{array}{c}\text { High. } \\
\text { High security and large } \\
\text { volume of data }\end{array}$ \\
\hline $\begin{array}{l}\text { Reader } \\
\text { Device } \\
\text { Cost } \\
\end{array}$ & $\begin{array}{c}\text { Low. } \\
\text { Cheap production } \\
\text { cost }\end{array}$ & $\begin{array}{c}\text { High. } \\
\text { Relatively expensive } \\
\text { CCD reader } \\
\end{array}$ & $\begin{array}{c}\text { High. } \\
\text { Number of reader } \\
\text { devices increases }\end{array}$ \\
\hline Data Error & $\begin{array}{c}\text { Low. } \\
\text { Allow little dust and } \\
\text { small movement }\end{array}$ & $\begin{array}{l}\text { High. } \\
\text { Reflection problem and } \\
\text { movement not allowed }\end{array}$ & $\begin{array}{c}\text { Good. } \\
\text { Not affected by dust or } \\
\text { movement }\end{array}$ \\
\hline $\begin{array}{l}\text { Business } \\
\text { Model } \\
\text { Scalability }\end{array}$ & $\begin{array}{c}\text { High. } \\
\text { Can be adapted to } \\
\text { various applications } \\
\text { based on WAP/Java }\end{array}$ & $\begin{array}{c}\text { Low. } \\
\text { Limitation of applica- } \\
\text { tions and Barcode- } \\
\text { based information }\end{array}$ & $\begin{array}{c}\text { Low. } \\
\text { Additional h/w chip } \\
\text { needed. But, good for } \\
\text { business area which } \\
\text { requires high security. }\end{array}$ \\
\hline
\end{tabular}

A new mobile payment method is proposed to solve the problems of existing payment methods. This method can be applied to the most mobile phones or devices already in use by updating embedded software without additional hardware modules.

\section{Light Signal Based Mobile Payment System}

The proposed mobile payment method transmits payment related information using the backlight of devices which is adopted in most mobile phones and embedded devices, thus eliminates the need of supplying new customized devices. The payment information using backlight signal is called virtual mobile card. The virtual mobile card based payment method has the following characteristics.

- The software application program is downloaded to the virtual machine of a phone or embedded devices.

- The optical source such as LCS backlight or keypad backlight of existing phones or devices is used for information transmission including software download and payment.

- Various types of security management solutions can be implemented by software.

- Large volume of card information data can be adopted as long as the embedded memory size allows.

- The card information can be downloaded by wireless connection immediately after the subscription. 
- CRM (Customer Relationship Management) and other applications can be easily applicable by coordination with phone number information.

- The cost of optical reader device is relatively cheap compared with CCD type readers or IR/RF type readers.

The virtual mobile card is downloaded from control server. The control server first sends the Callback URL which contains WAP address in the SMS page, and the users of phones or embedded devices access the address and download the application program and information. The mobile payment procedure is similar to the mobile game play procedure. The display device of a phone is attached to the photo receiver and the request and reply data is transmitted between the PCs in the branch office and the server in the main office as shown in Fig. 1.

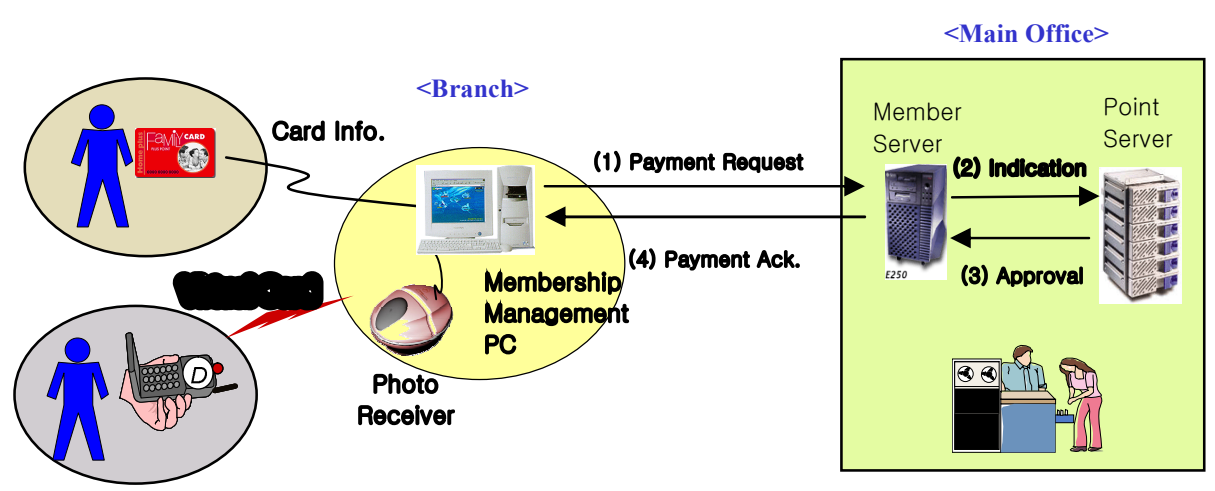

Fig. 1. Use of virtual mobile card for mobile payment

Our mobile payment system using a light signal consists of three parts: a mobile phone for generating a predetermined light signal; a photo receiver for converting the received light signal to an electrical signal, encrypting the electrical signal, and generating the encrypted electrical signal as an output signal; and the control server for authenticating payment by using the output signal of the photo receiver.

Fig. 2 is a block diagram showing a mobile phone payment system. The system comprises a mobile phone 111 , a photo receiver 121 , and a control server 131 .

In general, the mobile phone 111 has a display unit such as an LCD, an EL, and an organic EL illuminated with a backlight. Some types of the mobile phone 111 may have a keypad illuminated with a keypad-dedicated backlight such as a blue LED. In the mobile phone payment system, a light signal is generated in a form of pulses by turning on and off the backlight of the mobile phone based on payment-related information. In other words, the light signal contains the payment-related information. Therefore, the user of the mobile phone can make payments by using his or her mobile phone.

In order to use the mobile phone payment system 101, the user accesses the control server 131 to subscribe to the mobile phone payment service by transmitting his or her personal information to the control server 131. The personal information includes identification (ID) information, a credit card number, an E-mail address, E-money 


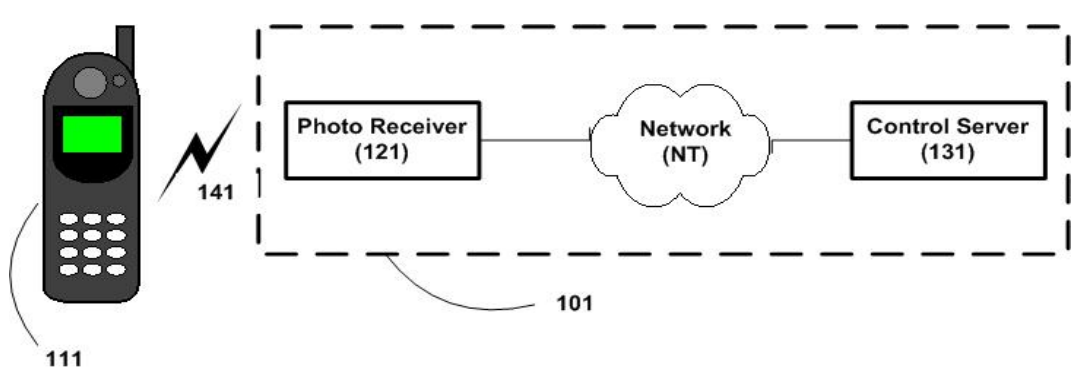

Fig. 2. Block diagram showing a mobile payment system

information, and a phone number of the user. The control server 131 stores the personal information in a data storage unit. The user downloads a program used for the mobile phone payment service from the control server 131 and installs the program in the mobile phone 111 .

The user can pay a charge by using the mobile phone 111 . The charge includes, for example, a charge for a game machine and a roller coaster, a charge for a gambling machine, an admission fee of a theater, a toll, a public vehicle fare, and a parking fee. In addition, the mobile phone 111 may be used to pay a price of gasoline, a vending-machine item. In addition, mobile phone 111 may be also used to transfer Emoney in ATM.

A photo receiver 121 decodes a light signal from a mobile phone, converting the light signal to an electrical signal, and transmitting the electrical signal to a control server. The photo receiver comprising: a photo sensor for receiving a light signal from a mobile phone, and converting the light signal into an electrical signal; a data error determination unit for receiving the electrical signal of the photo sensor and determining an error of the electrical signal; a control unit for transmitting the electrical signal of the photo sensor to the data error determination unit, generating a control signal based on the result of the error determination by data error determination unit, and generating the electrical signal if the electrical signal has no error; a display unit for displaying presence or absence of the error of the light signal in response to the control signal; and a communication unit for transmitting the electrical signal from the control unit to the control server.

The photo receiver may further comprise an encryption unit for encrypting the electrical signal transmitted from the control unit, and a communication unit for transmitting the encrypted signal by the encryption unit to the control server.

The display unit may comprise at least one of a third lighting device which is turned on, if a signal indicating that the payment-related information transmitted from the mobile phone is correct is transmitted from the control server, and a forth lighting device is turned on, if not, and the control unit may receive a predetermined signal from the control server via the communication unit and control the operation of the display unit in accordance with the received signal.

Fig. 3 is a waveform diagram showing pulses of a light signal 141 in Fig. 2, generated by a backlight of a mobile phone 111 used for a mobile payment system. The light signal 141 is partitioned into a starting frame $t 1$, an information frame $t 2$, and an 


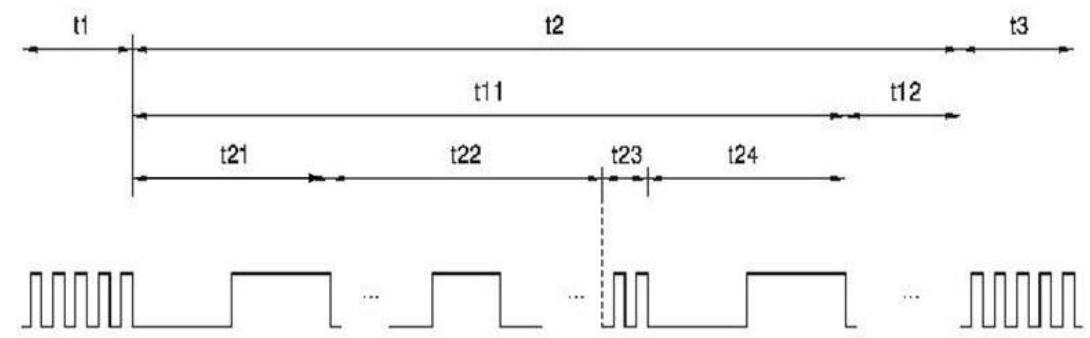

Fig. 3. Waveform diagram showing pulses of a signal generated by a backlight

ending frame $\mathrm{t} 3$. The starting frame $\mathrm{t} 1$ comprises a plurality of short pulses to indicate the starting point of the light signal 141. The information frame $\mathrm{t} 2$ comprises a plurality of pulses generated based on the payment-related information. The ending frame t3 comprises a plurality of pulses to indicate the ending point of the light signal 141 . The photo receiver may further comprise an encryption unit for encrypting the electrical signal transmitted from the control unit, and a communication unit for transmitting the encrypted signal by the encryption unit to the control server. Fig. 4 shows the block diagram and implemented prototype of photo receiver.

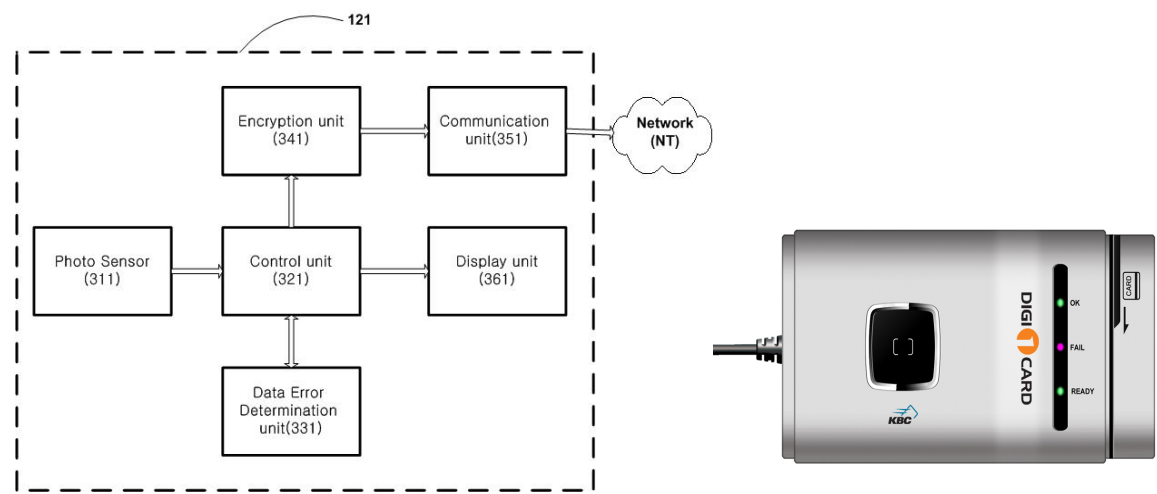

Fig. 4. Block diagram and prototype of a photo receiver

Fig. 5 is a flowchart showing a mobile phone payment method.

The mobile payment method is comprised of the following steps: (a) downloading the payment-related information of the user from the control server to the mobile phone and storing the payment-related information in the mobile phone; (b) converting the payment-related information into a binary code data in response to the user's request; (c) generating a light signal having a series of pulses by turning on and off a backlight of the mobile phone based on the binary code data and transmitting the light signal to the photo receiver; (d) receiving the light signal in the photo receiver, converting the received light signal into an electrical signal and transmitting the electrical signal from the photo receiver to the control server; (e) receiving the electrical signal, 


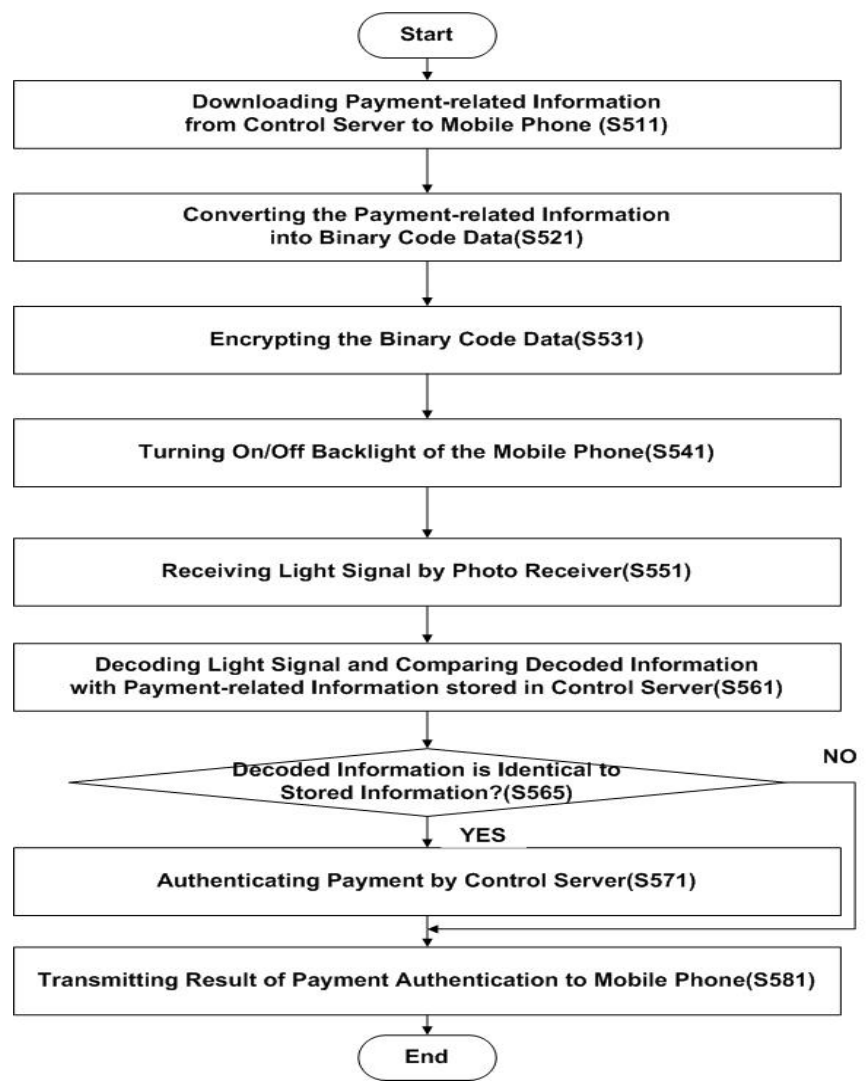

Fig. 5. Flowchart showing a mobile payment procedure

comparing payment-related information contained in the electrical signal with the payment-related information of the user stored in the control server and determining whether or not the transmitted payment-related information is correct; (f) if the transmitted payment-related information is correct, authenticating the user's payment; and (g) transmitting the result of the determination of the step (e) from the control server to at least one of the mobile phone and the photo receiver.

The step (b) may further comprise a step of encrypting the binary code data, and the step (e) may further comprise a step of decoding the received electrical signal.

\section{Conclusion}

A mobile payment system was proposed for mobile phone or embedded devices. The system consists of mobile device, photo receiver, and control server. The payment related information is downloaded from the control server to the user device. The new method provides an economic and efficient solution to mobile payment system using light signal. It is possible to make payments by using a mobile payment system being implemented by updating embedded software of the mobile phone or devices without 
additional hardware modules. Therefore, it is possible to reduce production costs of mobile phones and mobile payment systems. The measurement and comparison of performance such as recognition speed, error rate, and response time with other systems will be our future work, as well as in-depth study for security and privacy problems incurred by mobile payment systems. This work is subject to patent pending [11].

\section{References}

1. Zheng, X., Chen, D.: Study of Mobile Payments System, Proceedings of International Conference on E-Commerce, (2003) 24-27

2. Mallat, N., Tuunainen, V.K.: Merchant Adoption of Mobile Payment Systems, Proceedings of International Conference on Mobile Business, (2005) 347-353

3. Pousttchi, K., Zenker, M.: Current Mobile Payment Procedures on the German Market from the View of Customer Requirements, Proceedings of Workshop on Database and Expert Systems and Applications, (2003) 870-874

4. Delic, N., Vukasinovic, A.: Mobile Payment Solution - Symbiosis between Banks, Application Service Providers and Mobile Network Operators, Proceedings of International conference on Onformation Technology: New Generations, (2006) 346-350

5. Lee, O.: Sound-based Mobile Payment System, Proceedings of International Conference on Web Services, (2004) 820-821

6. Gao, J., Edunuru, K., Cai, J., Shim, S.: A Peer-to-Peer Wireless Payment System, Proceedings of International Conference on Mobile Commerce and Services, (2005) 102-111

7. Antovski, L., Gusev, M.: M-payments, Proceedings of International Conference on Information Technology Interfaces, (2003) 95-100

8. Korea Cyber Police Agency, http://www.police.go.kr, (2005)

9. http://www.ktfmembers.com, http://www.pheonixpark.co.kr

10. http://www.monetacard.co.kr, http://www.irda.org

11. Mobile Phone Payment Method and System, US patent pending, No. 10/893836 